\title{
Chemical risk assessment in a chemical laboratory based on three different techniques
}

\author{
Karimi Zeverdegani S, $\mathrm{PhD}^{1}$, Barakat $\mathrm{S}, \mathrm{Msc}^{2 *}$, Yazdi M, $\mathrm{Msc}^{3}$ \\ 1- Assistant Prof., Dept. of Occupational Health Engineering, School of Health, Isfahan University of Medical Sciences, Isfahan, \\ Iran. 2- MSc in Occupational Health, Dept. of Occupational Health Engineering, School of Health, Isfahan University of Medical \\ Sciences, Isfahan, Iran. 3- PhD Student in Statistics and Epidemiology, Dept. of Statistics and Epidemiology, School of Health, \\ Isfahan University of Medical Sciences, Isfahan, Iran.
}

\begin{abstract}
Received: November 2016, Accepted: February 2017

Background: The use of chemicals is essential in education resulting in exposure to these pollutant in a variety of chemical and research laboratories. Chemical contaminants in chemical laboratories are in different forms and chemical exposure risk assessment is important for choosing appropriate controls in protecting the health of operators, experts and students. For risk assessment in chemical exposures, several techniques were introduced that their use should be assessed. This research was done with the aim to introduce the most appropriate technique in chemical risk assessment by using three chemical risk assessment techniques.

Materials and Methods: This was a descriptive research done in one chemical laboratory. This research had been defined in several stages: in the first phase, the list of solid and liquid chemicals were prepared and full physicochemical properties of substances as well as toxicity and health risk of them were collected. Finally Chemical Risk Management Self-Assessment Model (Chem-SAM), University Of Wollingong (UOW) risk assessment and semi-quantitative risk assessment method (SQRA) methods were used and compared.

Results: There was significant difference between SQRA methods and UOW technique while no significant difference was observed between SQRA methods and Chem-SAM model.

Conclusions: All three techniques are simple, but the results were similar in SQRA methods and ChemSAM model, so these two methods can be replaced in chemical risk assessment. In order to control the identified risks, this research has recommended programs, control measures, improving local exhaust ventilation systems, personal protective equipment and training of personnel.
\end{abstract}

Keywords: Risk Assessment, Risk Management, Self-Assessment, Chemical, Model

\section{Introduction}

In most workplaces such as industry, laboratory and environment, new materials and chemicals are continually being introduced so that some adverse health effects following exposure to toxic chemicals can be caused. In many countries, manufacturers, suppliers and importers of substances are responsible for classifying the substances (1). Each year, new chemicals are introduced into the market so the number of people at risk of exposure to these toxic substances is increased (2).
Growing concern about the risk of chemical exposure in workplaces has led to determination of several techniques to identify and evaluate these hazards. Chemicals have different toxicity and risk assessment of chemicals determines the risk levels that they present to users (3). It can be said that these hazards have the potential to cause different types and severities of harm (4).

* Corresponding author: Samira Barakat, Dept. of Occupational Health Engineering, School of Health, Isfahan University of Medical Sciences, Isfahan, Iran.

E-mail: s_barakat@hlth.mui.ac.ir 
Human exposure to chemicals can be assessed by representative monitoring data or by model calculations based on available information on substances (1). In order to have a better understanding of chemical hazards and more efficient control of these, risk assessment is required. Chemical risk assessment is a process to assess the likelihood of the chemical or chemical operation causing harm to people and the severity of harm (5). Among the fundamental issues in toxicology are the definitions of exposure, hazard and risk. In the risk-assessment process, differentiation between reversible and irreversible effects are required (6). It can be said that risk is the likelihood of occurrence of an event in certain consequences (3). For different proposes, risk assessment and management in workplaces is needed. The first step in risk management is identifying all the chemicals that are used, handled, stored or generated in different workplaces (7). If one industry or workplace produce or generate toxic chemicals, it must manage these chemical risks (7). The assessment of human health risk consists of some stages. For example identification, compilation and integration of information about exposure to the chemical, hazards of a chemicals and finally determination of relationships between exposure, dose and adverse effects (8). In general, managing health and safety risks at workplaces involves: 1) identifying hazards, 2) risk assessment, 3) risk control, and 4) reviewing control measures (9). In addition to industries, other work environments where chemicals are routinely used also require chemical risk assessment. In addition to industrial and working environments, exposure to chemicals in educational environments such as chemical laboratory is required. In chemical laboratories, different people such as operators, teachers, researchers and students are exposed to pollutants in the forms of gases, vapors, and solid or liquid suspended particles. It should be noted that each of these chemicals has specific risks, and the effects caused by them depends on the type of chemical, duration of exposure, density and route of entry (2). In order to assess chemical risk, several models or methods have been defined.

To date, several assessments have been conducted by using the quantitative exposure monitoring technique (10). Examples of methods and models of risk assessment are Chemical Risk Management Self-Assessment Model (Chem-SAM) (11), UOW risk assessment method (12) and semi-quantitative risk assessment method (SQRA) (3). Generally little research has been conducted on chemical risk assessment in research laboratories. Hunadia Husin et al. conducted a study with the purpose of identification and evaluation of the risks involved and the level of exposure to chemicals handled at the labs (13). Our study aimed to assess chemicals risks in a chemical laboratory including various types of toxic substances that different people were exposed to. The purpose of this paper was to introduce and describe a methodology for risk assessment and comparison of two methods and one model in chemical risk assessment. Evaluation methods included Chem-SAM (11) and UOW risk assessment (12) that was previously unused in papers and SQRA which has been used in several studies (3).

\section{Material and Methods}

This was an analytical-descriptive research that was carried out in one chemical laboratory in 2014. This research consisted of five stages: 1) preparing the list of chemicals in one laboratory, 2) chemical risk assessment with Chem-SAM model, 3) chemical risk assessment with UOW method, 4) chemical risk assessment with SQRA method, and 5) statistical analysis.

Data collection: To collect the full list of toxic chemicals, all the packaging and labels were checked and toxic data about these chemicals 
had been retrieved. For other parameters in risk assessment (exposure, controls, chemical reactions, etc.), walking in the lab and seeing how people work, examining the controls such as ventilation systems and other equipment were carried out.

Chem-SAM model: This model was developed by Sandia National Laboratories' international chemical threat reduction department in partnership with the U.S. department of state (11). Chem-SAM model consists of four steps: 1. define the chemical assets (completed by filling out the survey questions for any chemicals and to complete the survey, for each question, select the value between 0 and 4 that best represents the chemical properties), 2 . define the potential adversaries: (the tool does consider those persons with authorized access to chemicals and those individuals who do not have authorized access to the chemicals), 3. calculate the chemical security risk (the chemical security risk is viewable as a relative number between 0 and 4 or as a graph) and 4. determine risk acceptability (based upon the relative risks that was provided, the facility/laboratory must determine this risk) (11). In Chem-SAM model, 87 questions are asked and results are shown for insiders and outsiders about theft risk, sabotage risk near populated area and sabotage risk near industrial area in five ranges: very low, low, moderate, high and very high (11) (Figure1).

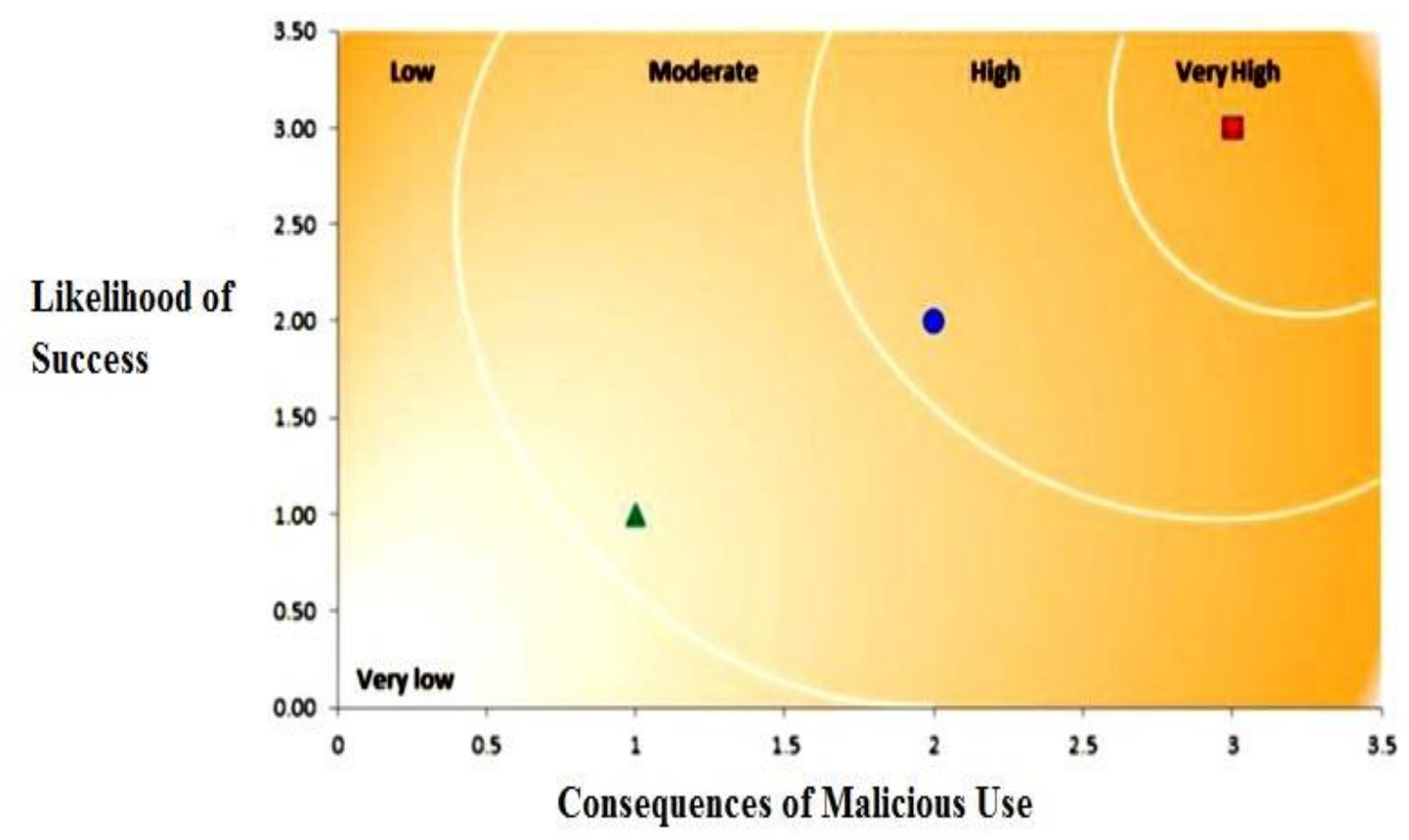

Figure 1: Output of Chem-SAM model

UOW risk assessment: In this approach, a single form is used to assess a laboratory experiment and there are eight steps in risk assessment: 1) name and location of experiment, and the date when the assessment was completed, 2) description of task/guidelines referenced, 3) hazard identification-equipment used and experimental design, 4) hazard identification-materials (hazardous substance reactant/products, flammable, toxic, corrosive, harmful, irritant, oxidizing), 5) controls adopted for risk minimization (flammability, toxicity, 
body contact, reactivity, chronic health), 6) further risk control measures, 7) the risk matrix, and 8) conclusion of risk assessment to health (In consultation with the supervisor/senior colleague, the laboratory worker should make a judgement as to level of risk). Risk level was obtained in 5 levels including: Extreme (E), High (H), Medium (M), Low (L), Negligible (N) (12) (Table 1).

Table 1: UOW risk matrix

\begin{tabular}{|c|c|c|c|c|c|}
\hline \multirow{6}{*}{ Likelihood } & & \multicolumn{4}{|c|}{ Consequences } \\
\hline & & Major & Moderate & Minor & Insignificant \\
\hline & A & $\mathrm{E}$ & $\mathrm{E}$ & $\mathrm{H}$ & M \\
\hline & B & $\mathrm{E}$ & $\mathrm{H}$ & $\mathrm{M}$ & $\mathrm{M}$ \\
\hline & $\mathrm{C}$ & $\mathrm{H}$ & M & M & $\mathrm{L}$ \\
\hline & $\mathrm{D}$ & $\mathrm{M}$ & $\mathrm{M}$ & $\mathrm{L}$ & $\mathrm{N}$ \\
\hline
\end{tabular}

SQRA: In this technique, risk of chemical exposure is calculated using hazard and exposure rating. Hazard rating (HR) was obtained with respect to effect/hazard category or by acute toxicity. In the case that effect/hazard category is used; grade 1 and 5 represent minimum and maximum hazard, respectively. In acute toxicity, hazard rating is obtained with respect to LD50 and LC50 (grade 2 and 5). Exposure rating (ER) could be determined using exposure level and exposure index. Exposure level is used when air monitoring results are available but where air monitoring results are not available; exposure index is used to determine exposure rating. After determining exposure and hazard rate, risk level is calculated with the formula (risk = $(\mathrm{HR} * \mathrm{ER})^{1 / 2}$ ) or is fined in the risk matrix (Table2) (3).

Table 2: SQRA risk matrix

\begin{tabular}{|c|c|c|c|c|c|}
\hline${ }_{\mathrm{ER}} \mathrm{HR}$ & 1 & 2 & 3 & 4 & 5 \\
\hline 1 & $1(\mathrm{~N})$ & $1.4(\mathrm{~N})$ & $1.7(\mathrm{~L})$ & $2(\mathrm{~L})$ & $2.2(\mathrm{~L})$ \\
\hline 2 & $1.4(\mathrm{~N})$ & $2(\mathrm{~L})$ & $2.4(\mathrm{~L})$ & $2.8(\mathrm{M})$ & $3.2(\mathrm{M})$ \\
\hline 3 & $1.7(\mathrm{~L})$ & $2.4(\mathrm{~L})$ & $3(\mathrm{M})$ & $3.5(\mathrm{H})$ & $3.9(\mathrm{H})$ \\
\hline 4 & $2(\mathrm{~L})$ & $2.8(\mathrm{M})$ & $3.5(\mathrm{H})$ & $4(\mathrm{H})$ & $4.5(\mathrm{VH})$ \\
\hline 5 & $2.2(\mathrm{~L})$ & $3.2(\mathrm{M})$ & $3.9(\mathrm{H})$ & $4.5(\mathrm{VH})$ & $5(\mathrm{VH})$ \\
\hline
\end{tabular}

SQRA: Semi-quantitative risk assessment method; HR: Hazard rating; ER: Exposure rating; VH: Very high; H: High; M: Medium; L: Low; N: Negligible

Data analysis: After data was collected by means of abovementioned techniques, statistical analysis was carried out with SPSS (Version 20.0, IBM Corporation, Armonk, NY, USA) and a graph was drawn using Excel software.

\section{Results}

Laboratory chemicals as well as results of risk assessment with three techniques are shown in table 3. 
Table 3: Chemical risk assessment by three techniques

\begin{tabular}{|c|c|c|c|c|c|c|c|}
\hline \multirow{2}{*}{ Chemical substances } & \multirow{2}{*}{$\begin{array}{l}\text { Physical } \\
\text { form }\end{array}$} & \multicolumn{2}{|c|}{$\begin{array}{c}\text { Chem-SAM } \\
\text { Facility chemical } \\
\text { security risk (outsiders) }\end{array}$} & \multicolumn{2}{|c|}{$\begin{array}{c}\text { Chem-SAM } \\
\text { Facility chemical } \\
\text { security risk (insiders) }\end{array}$} & \multirow{2}{*}{$\begin{array}{c}\text { Risk matrix } \\
\text { UOW risk } \\
\text { assessment }\end{array}$} & \multirow{2}{*}{$\begin{array}{c}\begin{array}{c}\text { Risk } \\
\text { matrix } \\
\text { SQRA }\end{array} \\
\begin{array}{c}\text { Risk } \\
\text { rating }\end{array}\end{array}$} \\
\hline & & $\begin{array}{l}\text { Theft } \\
\text { risk }\end{array}$ & $\begin{array}{l}\text { Sabotage near } \\
\text { populated area }\end{array}$ & $\begin{array}{l}\text { Theft } \\
\text { risk }\end{array}$ & $\begin{array}{l}\text { Sabotage near } \\
\text { populated area }\end{array}$ & & \\
\hline Toluene & Liquid & $\mathrm{M}$ & $M$ & $\mathrm{M}$ & $\mathrm{M}$ & $\mathrm{M}$ & $\mathrm{M}$ \\
\hline Formaldehyde & Liquid & $\mathrm{L}$ & $\mathrm{L}$ & $\mathrm{M}$ & $\mathrm{H}$ & $\mathrm{H}$ & $\mathrm{M}$ \\
\hline Xylene & Liquid & $\mathrm{M}$ & $\mathrm{M}$ & $\mathrm{M}$ & $\mathrm{M}$ & $\mathrm{M}$ & $\mathrm{M}$ \\
\hline Benzene & Liquid & $\mathrm{L}$ & $\mathrm{L}$ & $\mathrm{M}$ & $\mathrm{H}$ & $\mathrm{H}$ & $\mathrm{M}$ \\
\hline Ethylbenzene & Liquid & $\mathrm{M}$ & $\mathrm{M}$ & $\mathrm{M}$ & $\mathrm{M}$ & $\mathrm{M}$ & $\mathrm{M}$ \\
\hline Methanol & Liquid & $\mathrm{L}$ & $\mathrm{L}$ & $\mathrm{L}$ & $\mathrm{L}$ & $\mathrm{M}$ & $\mathrm{L}$ \\
\hline Ethyl acetate & Liquid & $\mathrm{L}$ & $\mathrm{L}$ & $\mathrm{L}$ & $\mathrm{L}$ & $\mathrm{M}$ & $\mathrm{L}$ \\
\hline Sulfuric acid & Liquid & $\mathrm{H}$ & $\mathrm{H}$ & $\mathrm{M}$ & $\mathrm{H}$ & $\mathrm{H}$ & $\mathrm{H}$ \\
\hline Nitric acid & Liquid & $\mathrm{M}$ & $\mathrm{M}$ & $\mathrm{M}$ & $\mathrm{M}$ & $\mathrm{M}$ & $\mathrm{H}$ \\
\hline Ethanol & Liquid & $\mathrm{L}$ & $\mathrm{L}$ & $\mathrm{L}$ & $\mathrm{L}$ & $\mathrm{M}$ & $\mathrm{L}$ \\
\hline Phosphoric acid & Liquid & $\mathrm{M}$ & $\mathrm{M}$ & $\mathrm{M}$ & $\mathrm{M}$ & $\mathrm{H}$ & $\mathrm{M}$ \\
\hline MEK & Liquid & $\mathrm{L}$ & $\mathrm{L}$ & $\mathrm{L}$ & $\mathrm{L}$ & $\mathrm{M}$ & $\mathrm{M}$ \\
\hline Triethanolamine & Liquid & $\mathrm{L}$ & $\mathrm{L}$ & $\mathrm{L}$ & $\mathrm{L}$ & $\mathrm{M}$ & $\mathrm{L}$ \\
\hline Acetone & Liquid & $\mathrm{L}$ & VL & VL & VL & $\mathrm{L}$ & $\mathrm{L}$ \\
\hline Carbon disulfide & Liquid & $\mathrm{M}$ & $\mathrm{M}$ & $\mathrm{M}$ & $\mathrm{M}$ & $\mathrm{H}$ & $\mathrm{H}$ \\
\hline Acetonitrile & Liquid & $\mathrm{M}$ & $\mathrm{M}$ & $\mathrm{M}$ & $\mathrm{M}$ & $\mathrm{M}$ & $\mathrm{M}$ \\
\hline Sodium hydrogen sulfide & Liquid & $\mathrm{L}$ & $\mathrm{L}$ & $\mathrm{L}$ & $\mathrm{L}$ & $\mathrm{L}$ & $\mathrm{L}$ \\
\hline Hydrofluoric Acid & Liquid & $\mathrm{M}$ & $\mathrm{M}$ & $\mathrm{M}$ & $\mathrm{M}$ & $\mathrm{M}$ & $\mathrm{M}$ \\
\hline Perchloric acid & Liquid & $\mathrm{M}$ & $\mathrm{M}$ & $\mathrm{M}$ & $\mathrm{M}$ & $\mathrm{M}$ & $\mathrm{M}$ \\
\hline Sodium sulfite & Solid & VL & VL & VL & VL & $\mathrm{L}$ & $\mathrm{M}$ \\
\hline Sodium chloride & Solid & $\mathrm{VL}$ & VL & VL & VL & VL & $\mathrm{M}$ \\
\hline Sodium carbonate & Solid & $\begin{array}{ll}\mathrm{VL} \\
\end{array}$ & VL & VL & VL & VL & $\mathrm{L}$ \\
\hline Sodium hydroxide & Solid & $\mathrm{L}$ & $\mathrm{L}$ & $\mathrm{L}$ & $\mathrm{L}$ & VL & $\mathrm{L}$ \\
\hline Potassium chromate & Solid & $\mathrm{L}$ & $\mathrm{L}$ & $\mathrm{L}$ & $\mathrm{L}$ & $\mathrm{H}$ & $\mathrm{VH}$ \\
\hline Silicon dioxide & Solid & $\mathrm{VL}$ & VL & $\mathrm{L}$ & $\mathrm{L}$ & & $\mathrm{H}$ \\
\hline Titanium dioxide & Solid & VL & VL & VL & $\mathrm{VL}$ & VL & $\mathrm{L}$ \\
\hline Boric acid & Solid & $\mathrm{VL}$ & VL & VL & VL & VL & $\mathrm{L}$ \\
\hline Ammonium heptamolybdate & Solid & $\begin{array}{ll}\mathrm{VL} \\
\end{array}$ & VL & VL & VL & VL & $\mathrm{L}$ \\
\hline $\begin{array}{c}\text { Ammonium molybdate } \\
\text { tetrahydrate }\end{array}$ & Solid & $\mathrm{L}$ & $\mathrm{L}$ & $\mathrm{L}$ & $\mathrm{L}$ & $\mathrm{VL}$ & $\mathrm{L}$ \\
\hline $\begin{array}{c}\text { 1-amino2-hydroxy-4- } \\
\text { naphthalenesulfonic acid }\end{array}$ & Solid & $\mathrm{L}$ & $\mathrm{L}$ & $\mathrm{L}$ & $\mathrm{L}$ & VL & $\mathrm{L}$ \\
\hline Sodium acetate & Solid & $\mathrm{VL}$ & VL & VL & VL & VL & $\mathrm{L}$ \\
\hline $\begin{array}{c}\text { Potassium dihydrogen } \\
\text { phosphate }\end{array}$ & Solid & VL & VL & VL & VL & VL & $\mathrm{L}$ \\
\hline
\end{tabular}

Chem-SAM: Chemical Risk Management Self-Assessment Model; SQRA: Semi-quantitative risk assessment method; VL: Very low; L: Low; M: Moderate, H: High; VH: Very high

Risk levels in three different methods are shown in figure 2. So the most frequent reported amounts of high and very low risk were for UOW and SQRA, respectively. 


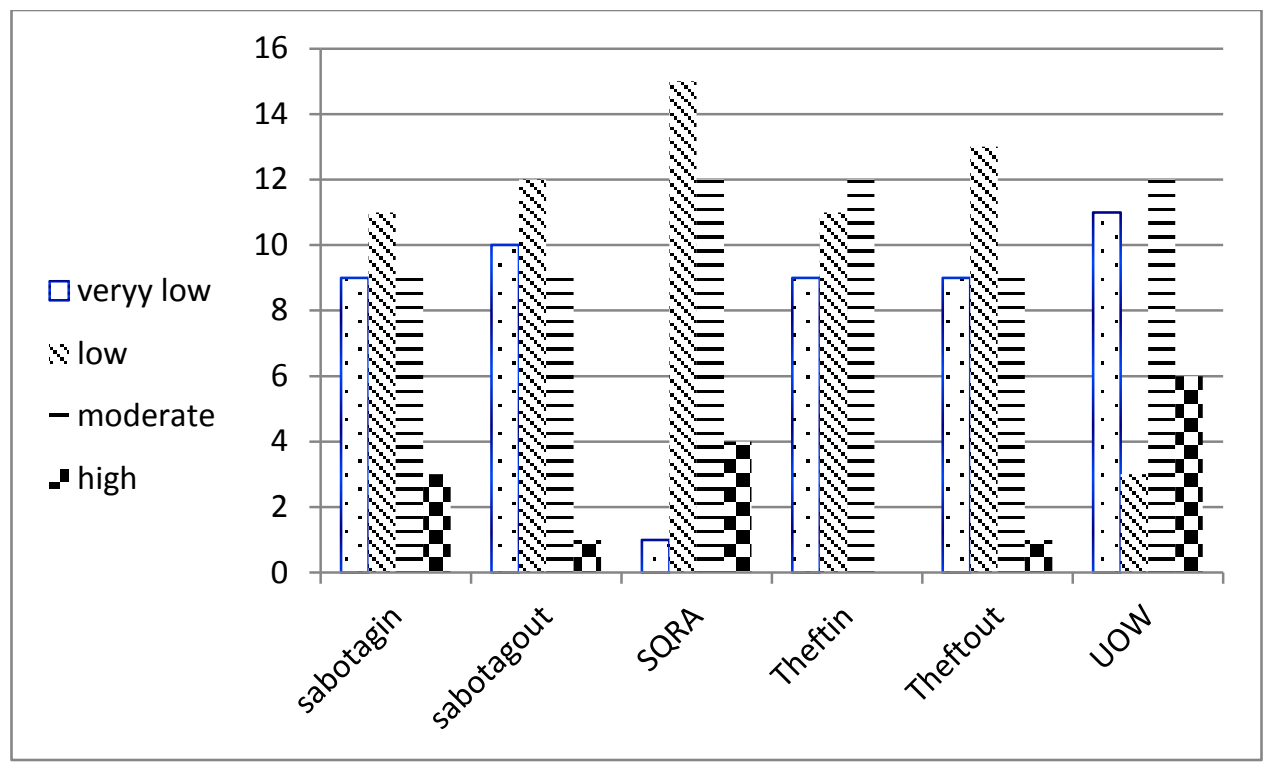

Figure 2: Risk levels in three risk assessment technique

To compare these, methods chi-square test with Bonferroni correction were used and all P-values were compared with level that was significantly modified with Bonferroni method, and P-values lower than 0.01 were significant (Table 4).

Table 4: Comparison of chemical risk assessment in three techniques

\begin{tabular}{cc}
\hline Technique & $\mathrm{P}$ \\
\hline SQRA-UOW & 0.001 \\
\hline SQRA-Chem-SAM theft out & 0.032 \\
\hline SQRA-Chem-SAM sabotage out & 0.019 \\
\hline SQRA-Chem-SAM theft in & 0.012 \\
\hline SQRA-Chem-SAM sabotage in & 0.055 \\
\hline
\end{tabular}

CHEM-SAM: Chemical Risk Management Self-Assessment Model; SQRA: Semi-quantitative risk assessment method

\section{Discussion}

In this research, 32 solid and liquid chemicals that were used in one chemical laboratory were listed (Table 2) and the risk of chemical exposure was obtained with two methods and one model. Three chemical risk assessment techniques in this research showed that most reports of high and very low risk levels were associated with UOW method. In SQRA, most have reported low and moderate risk level. The moderate level was similar in Chem-SAM theft in, SQRA and UOW methods. Also this level was similar in sabotage in, sabotage out and theft out. In this research none of these three methods showed very high risk and almost risk levels were consistent in all three techniques (Figure 2). Among these three techniques, only SQRA was used in literature; for example Bai et al. provided this method for urban gas pipelines by modifying Kent analysis method, and by using semi-quantitative risk matrix, the risk grade of the urban gas pipelines was obtained and this method is applicable to initial risk assessment of the urban gas pipelines which is planning construction (14). SQRA was used in 
some projects (15), also Karimi et al. used SQCRA as software to perform semiquantitative chemical risk assessment in workplace, and risk assessment was done for sulfuric acid, phosphoric acid, aluminum sulphate, nickel catalyst, and acetic acid (16). Wang proposed a semi-quantitative occupational chemical exposure risk predicting model that used toxicity index, exposure index and protection deficiency index to calculate exposure hazard index and concluded that the model does not separate acute and chronic effects of the exposed chemicals (10). Another study was conducted in the operation unit of an Iranian petrochemical company and the method of chemical risk assessment in the work environment was provided by the Department of Occupational Health in Singapore (2) and results showed that benzene and xylene were the most used chemicals in the studied industry (81\%), and were rated as moderate and high risk (2). Given that in previous researches SQRA have been carried out, in this research other methods were compared with this method. The only significant difference was between SQRA and UOW while no significant difference was observed between SQRA and Chem-SAM model (Table 3). This means that the results of SQRA and UOW differed but the results of Chem-SAM model were similar to SQRA. About the advantage of these methods, it could be said that Chem-SAM model is a simple and no-cost tool that helps to strengthen risk governance in chemical facilities by providing an assessment method that is systematic and replicable (11). UOW is a simple method but the results were different. However, these methods do not require sophisticated equipment. No significant difference was seen between SQRA and Chem-SAM model which could be due to similarity, variety, and full and complex parameters in these two methods. A few studies have been conducted on the risk of chemical exposure to research and chemical laboratories. Hunadia Husin in chemical health risk assessment at the chemical and biochemical engineering laboratory concluded that risk of hazardous chemicals at the laboratories was significant and control measures could be provided in a working environment that is safe for both the students and lab staff (13). Present study also showed that the risks of exposure to toxic substances in the chemistry lab is for staff, operators, students and other peoples. It is recommended that chemical risk assessment program be done in these environments. Three techniques that were used in this research were simple, responsive in this environments and somewhat had similar results.

\section{Conclusion}

In order to protect the health of people in a chemical laboratory, chemical risk assessments are required. Risk assessment can help to determine how severe a risk is, whether any existing control measures are effective, what action should be taken to control the risk (4), and for better risk assessment, consulting with those involved in the laboratory is needed. It should be noted that some processes will produce toxic chemicals as by-products or waste so these hazards may not be easily identified (7) and care must be taken in collecting information. Finally, proposed model and methods had almost the same results, were simple with no cost but still needed more research in other workplaces and environments.

\section{Acknowledgements}

The authors are grateful to the staff, operators and experts in chemical laboratory.

Conflict of interest: None declared. 


\section{References}

1. Herber RFM, Duffus JH, Christensen JM, Olsen E, Park MV. Risk assessment for occupational exposure to chemicals: A review of current methodology. Pure Appl Chem 2001; 73(6):9931031.

2. Beheshti MH, Firoozi Chahak A, Alinaghi Langari AA, Rostami S. Semi-quantitative risk assessment of health exposure to hazardous chemical agents in a petrochemical plant. Journal of Occupational Health and Epidemiology 2015; 4(1):1-8.

3. Singapoure. Ministry of Manpower. Occupational Safty and Health Division. A semi-quantitative method to assess occupatiobal exposure to harmful chemicals. Singapoure: Occupational Safty and Health Division, 2014. Report No.: 059764.

4. Australia, Safe Work Australia. How to manage work health and safety risks. Codes of Practice. Canberra: Safe Work Australia; 2011.

5. Hong Kong. Occupational Safety and Health Branch, Labour Department. Chemical safety in the workplace. Guidance notes on risk assessment and fundamentals of establishing safety measures. Hong Kong: The Commissioner for Labour, Labour Department; 2001.

6. Greim H, Snyder R. Toxicology and risk assessment: a comprehensive introduction. $1^{\text {st }}$ ed. Hoboken, New Jersey, United States: John Wiley \& Sons, Inc; 2008.

7. Australia, Safe Work Australia. Managing risks of hazardous chemicals in the workplace. Codes of Practice. Canberra: Safe Work Australia; 2012.

8. Swiss.World Health Organization. International Labour Organization and the United Nations Environment Programme Who human health risk assessment toolkit: chemical hazards. Geneve: World Health Organization; 2012. Harmonization Project Document No.: 8. Available from: http://www.inchem.org/documents/harmproj/har mproj/harmproj8.pdf

9. Australia, Safe Work Australia. Managing risks to health and safety at the workplace fact sheet. Codes of Practice. Canberra: Safe Work Australia; 2012.

10. Wang SM, Wu TN, Juang YJ, Dai YT, Tsai PJ, Chen CY. Developing a semi-quantitative occupational risk prediction model for chemical exposures and its application to a national chemical exposure databank. Int J Environ Res Public Health 2013; 10(8):3157-71.

11. Chemical Security Program. Chemical risk management self-assessment model (ChemSAM). Chemical Security Program. [Internet] . 2012. Available from: www.cspstate.net/resources/chem-sam/

12. Laboratory Work Risk Assessment. Australia: University of Wollongong, School of Chemistry; 2003 Aug.

13. Hunadia Husin SN, Mohamad AB, Sheikh Abdullah SR, Anuar N. Chemical health risk assessment at the chemical and biochemical engineering laboratory. Procedia Soc Behav Sci 2012; 60:300-7.

14. Bai YQ, Lv LH, Wang T. The application of the semi-quantitative risk assessment method to urban natural gas pipelines. Journal of Engineering Science and Technology Review 2013; 6(2):74-7.

15. Enbridge Northern Gateway Pipelin. SemiQuantitative Risk Assessment. Enbridge Northern Gateway Project. Calgary, Alberta Canada: Worley Parsons Canada Services Ltd.; 2013. Project No.: 407016-00013. Available from:http://ceaa.gc.ca/050/documents/p21799/85 851E.pdf

16. Karimi A, Jamshidi Slukloei HR, Eslamizad S. Designing SQCRA as a software to semiquantitative chemical risk assessment in workplace. Journal of Occupational Hygiene Engineering 2014; 1(2):47-56. 